\title{
Public health impacts of an imminent Red Sea oil spill
}

\author{
Benjamin Q. Huynh ${ }^{1 凶}$, Laura H. Kwong르. Mathew V. Kiang ${ }^{3,4}$, Elizabeth T. Chin ${ }^{1}$, \\ Amir M. Mohareb ${ }^{5,6}$, Aisha O. Jumaan7, Sanjay Basu ${ }^{8,9,10}$, Pascal Geldsetzer ${ }^{11,12}$, Fatima M. Karaki ${ }^{13,14}$ \\ and David H. Rehkopf 3,14
}

The possibility of a massive oil spill in the Red Sea is increasingly likely. The Safer, a deteriorating oil tanker containing 1.1 million barrels of oil, has been deserted near the coast of Yemen since $\mathbf{2 0 1 5}$ and threatens environmental catastrophe to a country presently in a humanitarian crisis. Here, we model the immediate public health impacts of a simulated spill. We estimate that all of Yemen's imported fuel through its key Red Sea ports would be disrupted and that the anticipated spill could disrupt clean-water supply equivalent to the daily use of 9.0-9.9 million people, food supply for 5.7-8.4 million people and 93-100\% of Yemen's Red Sea fisheries. We also estimate an increased risk of cardiovascular hospitalization from pollution ranging from 5.8 to $42.0 \%$ over the duration of the spill. The spill and its potentially disastrous impacts remain entirely preventable through offloading the oil. Our results stress the need for urgent action to avert this looming disaster.

S ince 2015, war and blockade in Yemen have made it the site of 'the world's worst humanitarian disaster." ${ }^{1}$ A major consequence has been the abandonment of the Safer, a deteriorating oil tanker moored 4.8 nautical miles off the Red Sea coast of Yemen. Concerns of a massive spill have arisen as the Safer, designated out-of-class since 2016 and not maintained since the start of the conflict, continues to deteriorate. The Safer contains 1.1 million barrels of oil, more than four times the amount spilled in 1989 by the Exxon Valdez ${ }^{2}$. The prospective spill threatens to harm the environment, economy, and public health of the countries bordering the Red Sea.

The possibility of a spill is increasingly likely. The visibly dilapidated Safer is single-hulled, meaning a breach will cause the onboard oil to spill directly into the sea. Water entered the engine room in May 2020 through a seawater-pipe leak, and the vessel's fire extinguishing system is non-operational ${ }^{3}$. A spill could occur due to a leak or combustion. A leak could arise through continued deterioration of the vessel's hull or by breach of the hull due to inclement weather; combustion could occur through build-up of volatile gases aboard the vessel or direct attack on the vessel. Ansar-Allah (colloquially known as the Houthis), a political and armed movement in control of North Yemen, currently has access to the Safer. As of writing, negotiations between the United Nations and the Houthis to inspect and repair the Safer have stalled indefinitely, and no long-term solutions, such as offloading the oil, have been publicly proposed.

Yemen is particularly vulnerable to the anticipated spill due to reliance on major ports near the Safer, Hudaydah and Salif, through which $68 \%$ of humanitarian aid enters the country. In the event of port disruption, rerouting humanitarian aid would be logistically difficult due to regional instability, lack of capacity at other ports, and the ongoing blockade, which severely limits the entry of supplies ${ }^{4}$. Overall, Yemen imports $90-97 \%$ of its fuel and $90 \%$ of its food supply ${ }^{5}$. Over half of Yemen's population depends on the humanitarian aid delivered at ports, with 18 million people requiring clean-water assistance and 16 million requiring food assistance ${ }^{1}$.

The anticipated spill also threatens the clean-water supply of the water-scarce Red Sea region. Oil could contaminate the desalination plants that are lined along the coast north of the Safer, thereby disrupting the clean-water supply to the region at large. For Yemen in particular, clean water is supplied mostly through groundwater pumps or water trucks, both of which require fuel. Previous fuel shortages caused by the blockade resulted in far-reaching public health impacts: for example, clean-water and sewage systems stopped operating, solid-waste collection was stalled, and electrical-grid disruptions led to blackouts affecting hospital operations, all of which contributed to a massive cholera outbreak in $2017^{6}$.

Yemen's fisheries, responsible for providing subsistence for 1.7 million people in the country, would also be threatened. Fishing was Yemen's second largest export before conflict began and continues to provide a source of income and food security in a country on the brink of famine. The sector has substantially declined in recent years due to conflict and fuel shortages; a massive oil spill would devastate an industry already struggling to subsist ${ }^{7-9}$.

Pollution from the spill, whether by evaporation or smoke from combustion, can cause cardiovascular and respiratory health issues. Fine particulate matter $\left(\mathrm{PM}_{2.5}\right)$ in general is known to increase the risk of hospitalization from cardiovascular and respiratory

'Department of Biomedical Data Science, Stanford University School of Medicine, Stanford, CA, USA. ²Division of Environmental Health Sciences, School of Public Health, University of California, Berkeley, CA, USA. '3epartment of Epidemiology and Population Health, Stanford University School of Medicine, Stanford, CA, USA. ${ }^{4}$ Harvard FXB Center for Health and Human Rights, Harvard University, Boston, MA, USA. ${ }^{5}$ Division of Infectious Diseases, Massachusetts General Hospital, Boston, MA, USA. ${ }^{6}$ Department of Medicine, Harvard Medical School, Boston, MA, USA. ${ }^{7}$ Yemen Relief and Reconstruction Foundation, Mercer Island, WA, USA. ${ }^{8}$ Center for Primary Care, Harvard Medical School, Boston, MA, USA. ${ }^{9}$ School of Public Health, Imperial College, London, UK. ${ }^{10}$ Institute of Health Policy, Management and Evaluation, University of Toronto, Toronto, Ontario, Canada. "Division of Primary Care and Population Health, Department of Medicine, Stanford University School of Medicine, Stanford, CA, USA. ${ }^{22} \mathrm{Heidelberg}$ Institute of Global Health, Heidelberg University, Heidelberg, Germany. ${ }^{13}$ Refugee and Asylum-seeker Health Initiative, Department of Medicine, University of California San Francisco, San Francisco, CA, USA. ${ }^{14}$ These authors contributed equally: Fatima M. Karaki, David H. Rehkopf. ${ }^{凶}$-mail: benhuynh@stanford.edu 

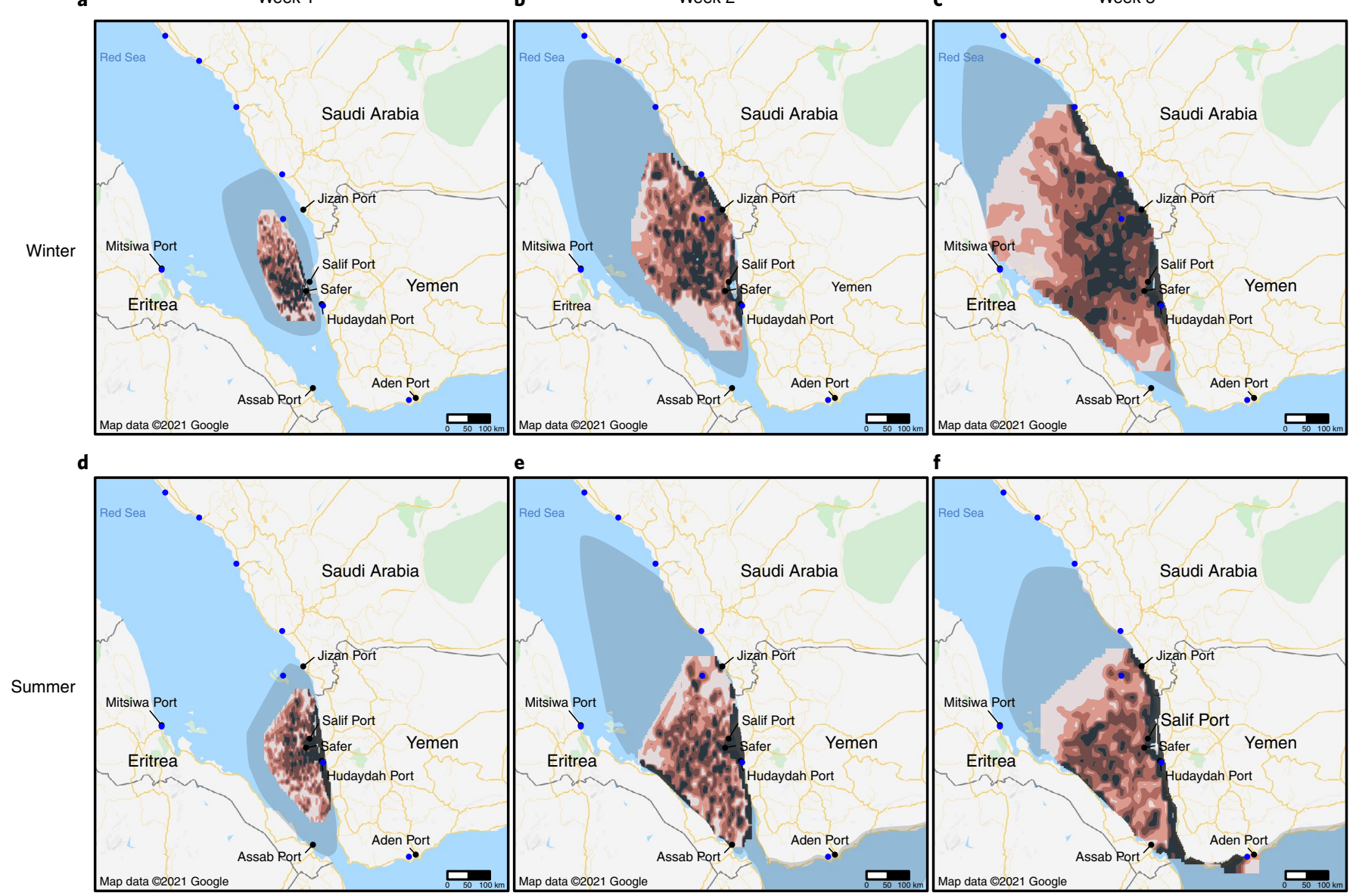

e $f$
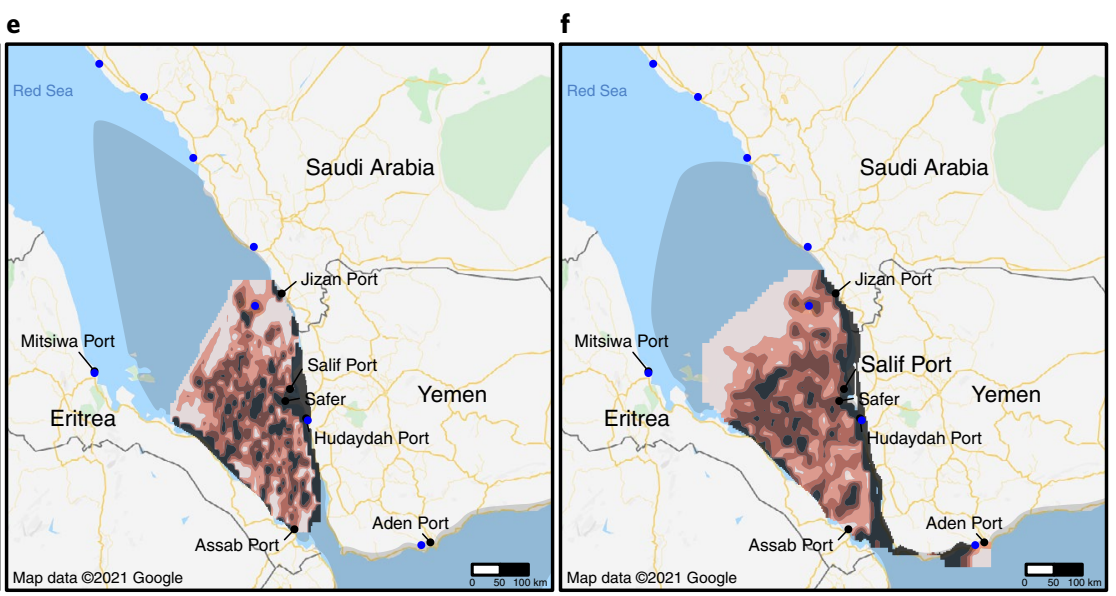

Percentile

$(0,20)$

$(20,40)$

$(40,60)$

$(60,80)$

$(80,100)$

Fig. 1 | Simulated surface oil concentration. a-f, Average surface oil concentration of 1,000 simulated spills in the winter (a,b,c) and in the summer $(\mathbf{d}, \mathbf{e}, \mathbf{f})$. Columns denote progress of the 1,000 spills after one week $(\mathbf{a}, \mathbf{d})$, two weeks $(\mathbf{b}, \mathbf{e})$ and three weeks $(\mathbf{c}, \mathbf{f})$. Coloured contours represent percentiles of average surface concentration over 1,000 simulated spills and can be interpreted as the expected surface concentration relative to other grid cells in the exposed area. Shaded region represents the area within which approximately $90 \%$ of spill trajectories are expected to fall. Blue dots represent desalination plants.

diseases, and pollution from oil spills in particular is known to cause a variety of health issues, ranging from psychiatric to respiratory symptoms $\mathrm{s}^{10-14}$. Resultant pollution from a spill could increase the burden on Yemen's under-resourced health systems and hinder clean-up efforts.

Major oil spills are known to have wide-ranging environmental and economic consequences. The danger that the Safer poses to the Red Sea's unique ecosystem has been documented ${ }^{2,15}$. However, the immediate public health impacts of the Safer spilling remain uncharacterized, and the extent to which the anticipated spill could disrupt humanitarian aid to Yemen critically informs the question of whether and with what urgency interventions should be deployed. Here we model the immediate public health impacts that would follow a major spill from the Safer. We stochastically simulate oil spills using historical data to assess likely spill and pollution trajectories and use these results to estimate disrupted access to fuel, food, and clean water, as well as initial air pollution-related health effects.

\section{Modelled spills reach key Red Sea ports}

We simulate the Safer spilling over a variety of historical weather conditions and find most simulated spills tend to move towards Yemen's northwest coast (Fig. 1). We observe seasonal variation from our models: in the summer, spills tend to move southeast and further along Yemen's coastline, but in the winter, spills tend to move north along the Red Sea coast. Uncertainty in the estimates indicates a wide range of possible trajectories across the Red Sea, showing the possibility of movement in either direction for both seasons. We estimate it will take 6-10 days for the oil to reach Yemen's western coastline. We estimate 51\% (95\% uncertainty interval: $46-54 \%$ ) of the oil will evaporate within 24 hours of leaking from the vessel, with the heavier components remaining on the water (Fig. 2). Modelled clean-up attempts-skimming, in situ burns, and dispersants-remove a negligible amount of oil within the first six days. Under optimistic conditions, clean-up interventions initially reduce evaporation rates slightly (probably due to the delayed impact of dispersants), and by six days we estimate $39.7 \%$ of the oil to remain floating, compared with $38.2 \%$ under evaporation alone (Fig. 2). If the spill spreads unmitigated for three weeks, oil will probably impede passage through the Gulf of Aden (Fig. 1).

Ports and desalination plants, crucial for providing fuel, food and water, stand to be disrupted by the spill. We estimate that two weeks after a spill, Yemen's key ports of Hudaydah and Salif will likely be directly impacted, with average surface oil concentrations that are in the 90th percentile compared with other exposed areas (Supplementary Table 1). We estimate that by three weeks, a spill could reach as far as the port of Aden (outside of the Red Sea) and 


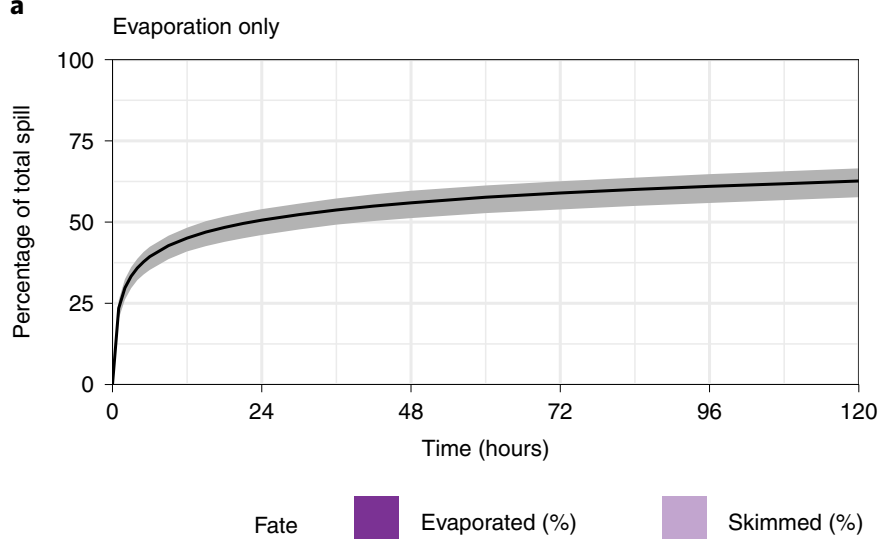

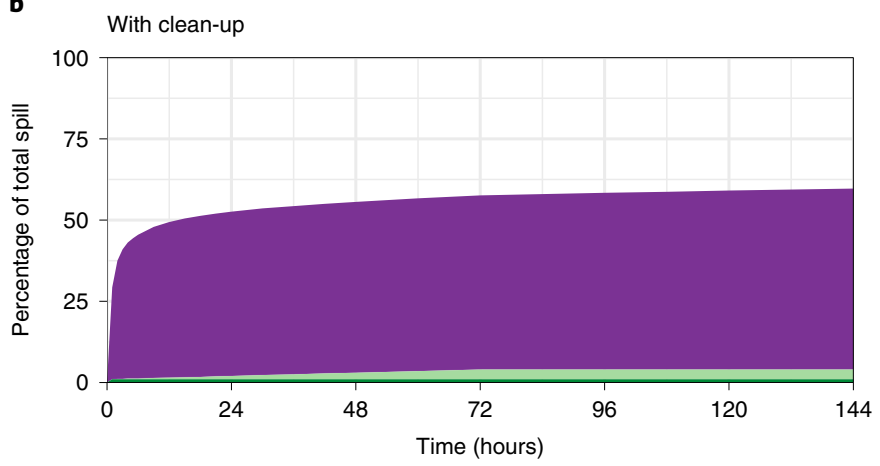

Chemically dispersed (\%)
Burned (\%)

Fig. 2 | Oil-fate scenarios. a, Oil-spill evaporation over time. Black line indicates mean, grey ribbon indicates 95\% uncertainty interval, defined as the 2.5 th and 97.5th percentiles of values across 1,000 Monte Carlo simulations. b, Oil fate under optimistic clean-up conditions. Coloured regions denote different oil removal methods.

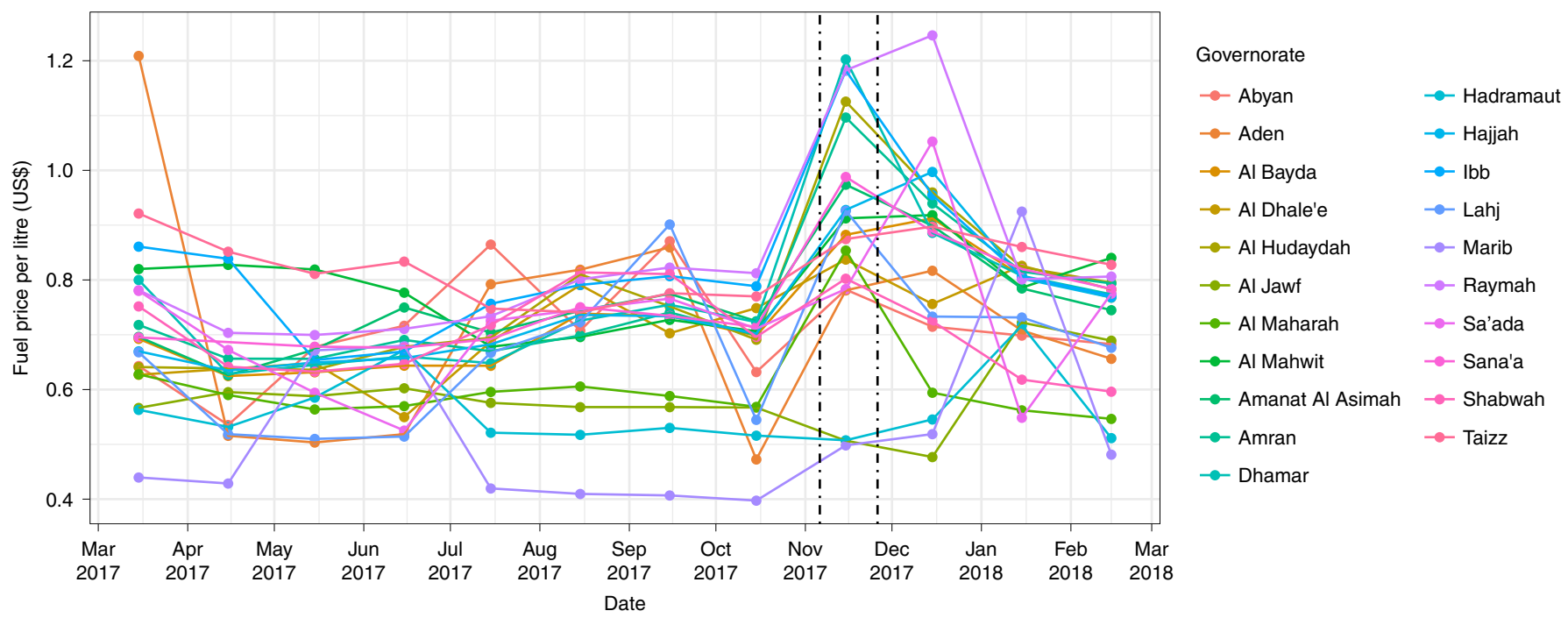

Fig. 3 | Fuel prices by governorate, March 2017-March 2018. Dashed lines denote the start and end of full port closures in Yemen.

the desalination plants and ports in Eritrea and Saudi Arabia (Fig. 1, Supplementary Table 1 and Supplementary Figs. 1-6).

\section{Expected port closures disrupt access to aid}

The spill and subsequent port closures will disrupt maritime transport across the Red Sea, rerouting many shipments around Africa. We estimate that for each month of Red Sea port closure, delivery of 200,000 (180,000-250,000) metric tons of fuel for Yemen will be disrupted, equivalent to $38 \%$ of the national fuel requirement ${ }^{16}$. We expect fuel prices in Yemen to spike as a consequence; when the blockade was tightened to fully close ports in November 2017, fuel prices sharply rose across the country, with prices in Hudaydah increasing $72 \%$ in the following month (Fig. 3).

The oil spill will also threaten clean-water supply, equivalent to the daily use of an estimated 1.0-1.9 million people through potential contamination of desalination plants. In the Red Sea region, we estimate potential disruption of desalination plants responsible for a total of $77,000 \mathrm{~m}^{3} \mathrm{~d}^{-1}$ of clean water in the summer and $362,000 \mathrm{~m}^{3} \mathrm{~d}^{-1}$ in the winter (Supplementary Table 2). We additionally expect water access in Yemen to be severely disrupted by fuel shortages if the spill closes ports; during the full port closures in November 2017, 8 million people in Yemen lost access to running water since accessing water typically depends on fuel-powered pumps or water trucks $s^{5,17}$.

Similarly, food security will be threatened by potential food aid disruptions and fishery closures. In the event of Yemen's Red Sea ports closing within two weeks of the spill, food aid will be disrupted for an estimated 5.7 (3.7-8.1) million people who currently require food assistance. We estimate that if Aden's port also closes, a total of 8.4 (5.4-11.9) million people will not receive food aid. We estimate the spill threatens $66.5-85.2 \%$ of Yemen's Red Sea fisheries within one week, and 93-100\% of Yemen's Red Sea fisheries within three weeks, depending on the season. In the summer, even $2.6 \%$ of Yemen's Gulf of Aden fisheries are threatened within three weeks (Supplementary Table 3).

\section{Air pollution increases hospitalization risk}

We predict moderate short-term health effects from air pollution, with estimates for the average increased risk of cardiovascular and respiratory hospitalizations ranging from 5.8\% (0-7.5\%) across $11.3(0-27)$ million person-days for a slow-release winter spill to $31.2 \%(6.5-50.5 \%)$ across 19.5 (0.4-24.2) million person-days for a fast-release summer spill (Table 1). Combustion would increase 
pollution, with estimates for the average increased risk of cardiovascular and respiratory hospitalizations ranging from $6.7 \%(5.2-$ $7.9 \%)$ across 22.3 (1.2-41.8) million person-days for a slow-release winter spill to $42.0 \%$ (21.9-61.4\%) across 22.7 (17.0-26.0) million person-days for a fast-release summer spill. Seasonality effects are present, with simulated air pollution travelling east into Yemen during the summer and west into the sea during the winter (Fig. 4). In some winter simulations, pollution did not reach the Yemeni population at all. Air pollution is highest in the immediate vicinity of the oil, reaching $\mathrm{PM}_{2.5}$ levels as high as $1,600 \mathrm{ug} / \mathrm{m}^{-3}$, corresponding to a $530 \%$ (460-590\%) increased risk of cardiovascular and respiratory hospitalization for individuals directly exposed to the oil, such as clean-up workers.

\section{Discussion}

The public health impacts of a spill from the oil tanker Safer are expected to be catastrophic, particularly for Yemen. Disruption of fuel imports is anticipated to shut down hospitals and essential services, at a time when Yemen already faces fuel shortages and only $50 \%$ of its health services are functional ${ }^{18,19}$. Both fuel shortages and contamination of desalination plants are expected to worsen an existing water crisis, potentially leading to a resurgence of water-borne infectious diseases ${ }^{20-23}$. Disruption to food aid would probably increase food prices and exacerbate an ongoing famine ${ }^{1}$. The spill threatens to disrupt nearly all of Yemen's Red Sea fisheries, which would worsen food security and exacerbate Yemen's displacement crisis as workers seek new employment ${ }^{7-9,19}$. Imports of medical supplies from aid groups would probably also be disrupted, further destabilizing health services ${ }^{22,24}$. Our modelling indicated that clean-up would be slow even under optimistic conditions; actual clean-up efforts would potentially be further prolonged and logistically difficult given the conflict in the region and sea mines in the water. Ports would potentially remain closed until sufficient clean-up has occurred; if ports were to prematurely reopen, ships would risk remobilizing the oil and furthering environmental damage. The air pollution from the spill may be moderate compared with the supply disruptions from the spill, but clean-up workers, essential to curbing impacts of the spill, may be at high risk of hospitalization ${ }^{13,25,26}$, and the pollution with its resultant increases in respiratory hospitalizations would potentially further strain an already under-resourced health-care system ${ }^{27}$. Personal protective equipment could substantially mitigate pollution harms, but the ongoing medical equipment shortage would probably be exacerbated by port closures ${ }^{28,29}$.

The long-term and global impacts of the spill, although outside the scope of our modelling analysis, are also potentially severe. Ecological and environmental impacts through wildlife endangerment and coastline contamination from large oil spills can persist for years or decades ${ }^{30,31}$. In particular, the spill threatens the Red Sea coral reefs, studied for their unique resilience to seawater warming $^{32}$. Further, the spill could hinder global trade through the vital Bab el-Mandeb Strait, 29 kilometres wide at its narrowest point, through which $10 \%$ of the global shipping trade passes. Exclusion zones created for clean-up could reroute traffic, and shipments will be delayed as ships potentially exposed to oil will require cleaning.

Kleinhaus et al. warned of the danger the Safer poses to the Red Sea's ecosystem and performed single-simulation analysis, finding that particles in February flow north and particles in August flow south ${ }^{2}$. Our spill-trajectory analysis strengthens their findings by explicitly modelling the Safer's oil properties and thoroughly assessing the range of possible spill trajectories through thousands of Monte Carlo simulations over historical data. We find their simulated trajectories to be consistent with ours, and we validate their claim that winter spills tend to travel north and summer spills tend to travel south. However, we emphasize that our primary finding, that a spill from the Safer could lead to catastrophic public
Table 1 | Population-weighted average increased risk (IR) and exposed populations for cardiovascular and respiratory hospitalizations from air pollution over various scenarios and spill durations

\begin{tabular}{|c|c|c|}
\hline Scenario & Average IR (\%) & Person-days \\
\hline $\begin{array}{l}\text { Summer, fast-release, } \\
\text { leak }\end{array}$ & $31.24(6.52,50.56)$ & $19.46(0.38,24.18)$ \\
\hline $\begin{array}{l}\text { Winter, fast-release, } \\
\text { leak }\end{array}$ & $16.2(6.82,22.59)$ & $4.52(0.85,8.73)$ \\
\hline $\begin{array}{l}\text { Summer, } \\
\text { slow-release, leak }\end{array}$ & $13.9(3.95,22.01)$ & $53.29(0.11,79.87)$ \\
\hline $\begin{array}{l}\text { Winter, slow-release, } \\
\text { leak }\end{array}$ & $5.83(0,7.48)$ & $11.34(0,27.19)$ \\
\hline $\begin{array}{l}\text { Summer, fast-release, } \\
\text { fire }\end{array}$ & $41.96(21.88,61.41)$ & $22.65(17.02,26)$ \\
\hline $\begin{array}{l}\text { Winter, fast-release, } \\
\text { fire }\end{array}$ & $19.45(13.15,24.72)$ & $6.6(2.39,9.98)$ \\
\hline $\begin{array}{l}\text { Summer, } \\
\text { slow-release, fire }\end{array}$ & $17.72(10.37,25.09)$ & $68.21(36.95,82.63)$ \\
\hline $\begin{array}{l}\text { Winter, slow-release, } \\
\text { fire }\end{array}$ & $6.65(5.16,7.9)$ & $22.34(1.15,41.75)$ \\
\hline
\end{tabular}

Spill duration is equivalent to exposure duration. All intervals (in parentheses) denote $95 \%$ uncertainty intervals, defined as the 2.5 th and 97.5 th percentiles of simulated values. Exposed population is defined as having been exposed to $10 \mathrm{ug} \mathrm{m}^{-3}$ or more of $\mathrm{PM}_{2.5}$. Uses estimates from Burnett et al. ${ }^{12}$

health impacts, is true regardless of season due to the wide range of spill trajectories that we observe from our uncertainty analyses. Relatedly, a misinterpretation of seasonality may lead malicious actors to induce an oil spill during supposedly favourable conditions; we assert strongly that our analysis shows that substantial uncertainty in trajectory exists despite seasonality, and so all parties involved in the conflict stand to bear the burden of the spill.

Although our model accounts for a number of uncertainties associated with a future spill, some uncertainties remain. Our oil-spill model is averaged over simulations based on historical data, but spills often occur due to extreme conditions, so the actual spill may manifest differently than the scenarios we present. The data we use to model the spill and downstream effects are of variable quality, so our results may be affected by measurement error. Stored quantities of supplies could mitigate shortages in the event of port disruption, but such quantities are probably minimal as Yemen is already undergoing supply shortages, and price spikes would render supplies inaccessible for many ${ }^{5,24}$. Our model considers only the scenario of a full spill; we do not model, for example, the impacts of a minor leak in the hull. We do not provide expected durations for port and desalination plant closures since we are unable to predict the timing of clean-up efforts. In particular, it is difficult to predict the international response to the anticipated spill: some parties may prefer ports to remain closed to minimize environmental damage, and others may prefer them to open sooner to minimize supply disruptions. Our clean-up analysis does not consider how containment booms may change the spill trajectory, but booms would have limited ability to change the spill trajectory due to the size of the spill, wave heights in the Red Sea and lack of pre-existing capacity to respond immediately ${ }^{33,34}$. Our spill models do not explicitly model tides, and instead assume tidal currents to be implicitly measured in the currents data; the Red Sea has a small tidal range, so we do not expect this to substantially affect our model estimates ${ }^{35}$. Our plotted uncertainty regions for potential spill trajectories correctly identify the outer uncertainty particles of where spills may go but may 


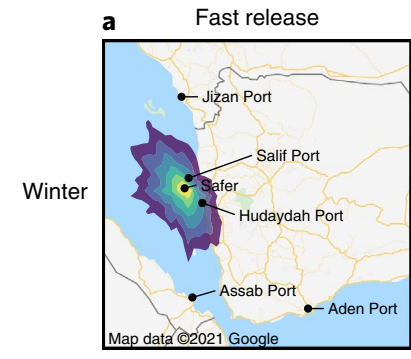

c

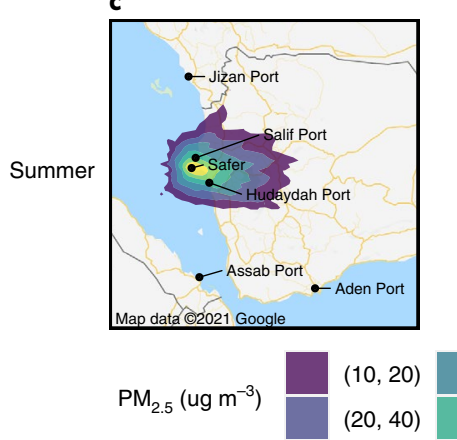

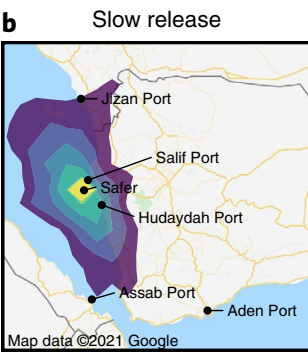

d

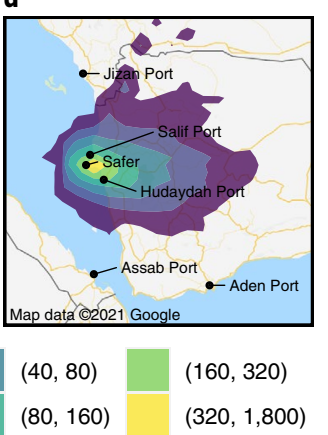

e

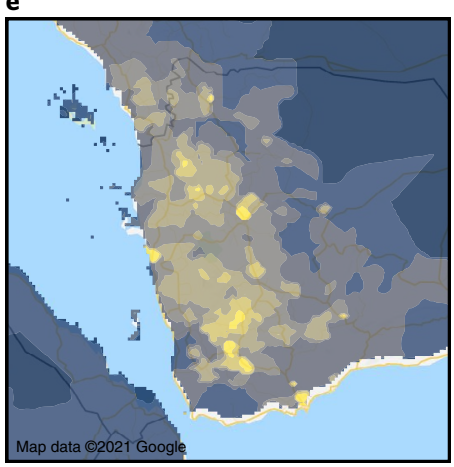

Population $\left(n \mathrm{~km}^{-2}\right.$ )

$(0,100)$

$(100,500)$

(500, 2,500)

$(2,500,5,000)$

$(5,000,10,000)$

$(10,000,25,000)$

$(25,000,500,000)$

Fig. 4 | Simulated air pollution concentration. a-d, Projected 24-hour average air pollution concentration at the end of spill in the winter (a,b) and summer (c,d) for fast-release spills (a,c) and slow-release spills (b,d). e, Population density plot.

overestimate the areas within the region as there may be pockets of sea where oil is less likely to travel due to patterns in winds or currents. However, our models also do not fully account for wave turbulence, so the affected spill area may be larger than we show. We also make the conservative assumption that ports will be disrupted only when oil directly reaches them. In reality, oil needs only to impede nearby maritime traffic to threaten port closure to prevent the environmental hazard of ships remobilizing the oil. Although we are unable to predict the exact probability of port closure, our spill analysis validates the claim that port closures are a distinct possibility, as agencies familiar with the situation have warned ${ }^{36}$. We thus do not believe that uncertainty in our spill models should qualitatively change our assessment of the potential downstream public health impacts as severe.

Our air pollution models are also subject to several levels of uncertainty. Our evaporation and combustion estimates are based partially on data from the Deepwater Horizon, which had light crude oil that was similar but not equivalent to the oil carried by the Safer. It is possible that the tanks aboard the Safer have already leaked and that some of the light components of the oil have already evaporated, which would reduce the amount of air pollution from the spill. We based our health impact assessments on single-pollutant health outcomes and do not explicitly model volatile organic compounds due to lack of data, but the $\mathrm{PM}_{2.5}$ from an oil spill is probably different from $\mathrm{PM}_{2.5}$ from other sources. Our estimates of the size of the population affected by pollution may be subject to measurement error in the original population dataset resulting from displacement or regional instability. We also consider only the risk of cardiovascular and respiratory hospitalization from oil exposure; oil spills are known to also have neurological, haematological, dermatological and psychiatric impacts ${ }^{13,14,26}$. Our modelling thus does not capture the full extent of health effects from oil exposure. Further, our modelling assumed the pollution is emitted from a single site (the site of the spill), but in reality it would be emitted from wherever the oil is spilled. Thus, our estimates of hospitalization rates are biased downwards since the pollution would probably be slightly closer inland.

Despite the uncertainty inherent to our modelling, our evidence demonstrates that an oil spill from the Safer poses an extreme public health risk to the people of the surrounding area, with Yemen bearing the largest impact. Our results show the spill will jeopardize access to fuel, food and water in Yemen, a country already facing shortages of all three. Other countries bordering the Red Sea will also incur the burden of the spill with port closures and disruptions to desalination plants. This public health disaster could be averted by finding a long-term solution to handling the oil aboard the Safer, underscoring the need for urgent action from the international community.

\section{Methods}

Data. For gridded wind data, we use the 2019 and 2020 surface wind ERA5 datasets from the European Centre for Medium-Range Weather Forecasts (ECMWF), with a 1 -hour temporal resolution and $1 / 4^{\circ}$ spatial resolution ${ }^{37}$. For gridded currents, sea temperature and salinity data, we use 2019 and 2020 data from the Hybrid Coordinate Ocean Model, with a 3-hour temporal resolution and $1 / 12^{\circ}$ spatial resolution ${ }^{38}$. For data on the properties of the oil, we use the National Oceanic and Atmospheric Administration's (NOAA's) Oil Library Project ${ }^{39}$. For data on fuel prices, we use a dataset from the World Food Programme ${ }^{40}$. We use fuel import data from the United Nations Verification and Inspection Mechanism for Yemen ${ }^{41}$. We used a variety of sources for data on desalination plant locations and capacity (Supplementary Table 2) ${ }^{42-44}$. For Yemen, locations for all desalination plants were not available, and the water capacities for the known plants were also unavailable. Therefore, to estimate the water capacity for each of the known plants in Yemen, we used the most recent available data on country-wide desalination capacity ${ }^{45}$ and divided it equally among the known plants. Food import estimates were derived from Yemen's port data ${ }^{46}$.

Oil-spill modelling. We modelled the spill using the pyGNOME library from NOAA to use their GNOME mode ${ }^{47}$. GNOME is a widely used Eulerian/ Lagrangian spill-trajectory model, modelling spills with Lagrangian elements within flow fields. Like most operational response tools, GNOME is able to model the oil transport and weathering processes of advection, diffusion, dispersion-entrainment, emulsification, evaporation, spreading, oil-shoreline interaction and dissolution. We chose NOAA's suite of modelling tools due to their history of being implemented operationally and validated against real-life environmental disasters as well as their widespread use among disaster response agencies ${ }^{48}$. As model inputs, we used the characteristics of the crude oil on board the Safer, Marib Light, as well as the historical currents and wind data of the region. We performed 1,000 Monte Carlo simulations each for both summer (June-August) and winter (December-February), varying time of day and date. Seasons were chosen on the basis of known current patterns in the Red Sea ${ }^{49}$. We restricted simulations to three-week timelines due to predictability limits inherent to oil-spill modelling and uncertainty in clean-up efforts ${ }^{50}$. 
Each simulation had 1,000 particles representing the oil trajectory based on historical weather conditions. Particles were sizeless and represented by surface oil concentration values and coordinates on a latitude-longitude grid rounded to three decimals, corresponding approximately to $100 \mathrm{~m} \times 100 \mathrm{~m}$. For each season, we simulated 1,000 spills with three-week timelines. At the end of weeks 1, 2 and 3 , we calculated the average surface concentration value at each point on the grid. We then used bilinear interpolation to calculate values between points. Given the uncertainty in the amount of oil that will be spilled, we converted the average surface concentration values from absolute values (average surface oil thickness, measured in metres) to relative values (average surface oil thickness relative to other exposed areas, measured in percentiles).

Each simulation also had 1,000 uncertainty particles that simulated the oil trajectory through parameter settings that assume extreme weather conditions. According to GNOME documentation, the area enclosed by the uncertainty particles represents where approximately $90 \%$ of spill trajectories are expected to fall ${ }^{51}$. We calculated the area enclosed by the uncertainty particles by computing the convex hull from the locations of all uncertainty particles from all 1,000 simulations and plotted it as the uncertainty region.

We repeated our spill analyses, varying spill duration, season, grid resolution and number of particles to assess how model output would change. Our original models assumed a 7-day spill; we repeated the models for a 24-hour spill. We further repeated the spill models for spring (March-May) and autumn (September-November). We also resimulated the spills using a coarser spatial resolution (latitude and longitude rounded to 2 decimal points, corresponding to approximately $1.1 \mathrm{~km} \times 1.1 \mathrm{~km})$ and higher number of particles $(10,000$ instead of 1,000) (Supplementary Figs. 3-5).

Oil fate. To calculate the fate of the oil, we used NOAA's Automated Data Inquiry for Oil Spills tool. As inputs, we used data on the oil type, gridded winds, gridded currents, water salinity and water temperature. We modelled oil fate for two scenarios: one with no clean-up (evaporation only) and one with extremely optimistic clean-up conditions. We restricted all weathering models to run for six days because they do not account for longer-term factors, such as biodegradation or photo-oxidation, that may affect the weathering rate ${ }^{47}$. To get a range of evaporation estimates, we performed 1,000 Monte Carlo simulations by randomly varying time and date. We calculated the mean and $95 \%$ uncertainty intervals, defined as the 2.5 th and 97.5 th percentiles across all simulations. For clean-up analyses, we made the optimistic assumptions that (1) clean-up would begin immediately after the spill occurs, and (2) oil recovery amounts over six days would be comparable to those of the 2010 Deepwater Horizon oil-spill clean-up. We modelled a skimmer with a recovery rate of 14 barrels per hour and $100 \%$ efficiency, in situ burning with an area of $70,000 \mathrm{~m}^{2}$ and $50 \%$ efficiency, and $15 \%$ of oil sprayed with dispersant at $20 \%$ efficiency, at $29^{\circ} \mathrm{C}$ and $42 \%$ salinity. The clean-up parameters were chosen to match the clean-up rate in the Deepwater Horizon oil spill. We used the amount of oil recovered by different clean-up methods in the Deepwater Horizon oil spill, scaled it from its 85-day clean-up time frame to our 6-day time frame and selected clean-up parameters that would recover this estimated amount of oil over 6 days $^{52}$. The weather values were selected to match the values from our previous Monte Carlo simulation analysis that maximized oil evaporation.

Air pollution modelling. For air pollution modelling, we used NOAA's Hybrid Single-Particle Lagrangian Integrated Trajectory (HYSPLIT) model ${ }^{53}$. HYSPLIT is an extensively used atmospheric transport and dispersion modelling framework using a hybrid Eulerian/Lagrangian approach to compute the trajectory of airborne particles as well as pollutant concentrations. We conducted simulations across four scenarios, varying seasons (summer and winter) and spill duration ( 24 hours for a fast-release spill and 72 hours for a slow-release spill). The spill duration is equivalent to the duration of pollutants being emitted. We used HYSPLIT's daily runs feature to conduct simulations for every three hours from January to March and June to August. Each simulation ran for 144 hours with pollutants emitted at sea level. Each simulation had 2,500 particles, with a concentration value for each particle. For each season and spill duration combination, we calculated the average pollutant concentration value at each point on a latitude-longitude grid rounded to three decimals. We used bilinear interpolation to calculate values between points. We assumed a full spill of 150,000 metric tons in all scenarios.

To get air pollution values in terms of fine particulate matter, we converted the initial oil release from barrels to micrograms, multiplied by the oil-to-particulate matter conversion rate calculated by Middlebrook et al. ${ }^{54}$, divided by the duration of the spill and multiplied by the concentration values estimated by the model. We calculated the population-weighted average increased risk of cardiovascular and respiratory hospitalization from the air pollution by multiplying the air pollution values by the increased risk and population share at each interpolated grid point. Our risk function relating $\mathrm{PM}_{2.5}$ exposure to cardiovascular and respiratory hospitalizations was derived from Burnett et al. ${ }^{12}$. Risk was averaged over person-days to compare across different spill durations. We calculated person-days by calculating the number of people exposed to at least $10 \mathrm{ug} \mathrm{m}^{-3}$ of $\mathrm{PM}_{2.5}$ and the duration for which they were exposed.
Due to uncertainty in the particulate matter conversion rate and increased risk of cardiovascular and respiratory mortality from fine particulate matter, we repeated this process through Monte Carlo simulation, varying those two parameters over 1,000 simulations each to propagate uncertainty. To propagate uncertainty, we varied two parameters over the simulations: the rate of conversion from surface oil to fine particulate matter and the increased risk (IR) of fine particulate matter with respect to cardiovascular and respiratory hospitalizations. Drawing on the point estimates and confidence intervals (CIs) reported from existing literature, we adopted the methodology from Khomenko et al. ${ }^{55}$ and computed the IR standard deviations as follows (where qnorm is the inverse of the standard normal cumulative distribution function):

$$
\ln (\mathrm{IR} \text { upper CI/IR lower CI }) /(2 \times \text { qnorm }(0.975))
$$

We assumed normal distributions and sampled from the reported mean and estimated standard deviation. The standard deviation for the fine particulate matter conversion rate is provided, so we used the reported estimate. We calculated the mean IR from our simulations and constructed $95 \%$ uncertainty intervals. If the lower uncertainty interval for the simulated IR was less than 0 , we assumed no increased risk of hospitalization. We also calculated the mean and $95 \%$ uncertainty intervals for the population affected over time, measured in person-days.

We repeated our air pollution analyses under several different scenarios. In addition to modelling 24-hour spills and 72-hour spills during different seasons, we modelled air pollution with and without combustion. For estimates of air pollution from combustion, we added the burned oil-to-particulate matter conversion rate from Middlebrook et al. ${ }^{54}$ to the existing evaporative conversion rate. We also varied the increased risk function since the estimate we used from Burnett et al. ${ }^{12}$ may not demographically reflect the population in Yemen. We thus performed the preceding calculations using respiratory hospitalization rates from Wei et al. ${ }^{11}$ and short-term $\mathrm{PM}_{2.5}$-related mortality rates from Kloog et al. ${ }^{10}$. Wei et al. ${ }^{11}$ used a Medicare population (mostly aged $65+$ ) that is more vulnerable to air pollution, which may reflect some subgroups in the Yemeni population, many of whom are malnourished and lack proper health services. Kloog et al. ${ }^{10}$ used full mortality records from the state of Massachusetts, used more modern methods than Burnett et al. ${ }^{12}$ and may more accurately reflect the younger age structure of Yemen than the Medicare population studied by Wei et al. ${ }^{11}$. We present results in terms of increased risk of hospitalizations instead of increased hospitalizations because the increased risk we calculate is relative to a baseline level of hospitalization risk, which we do not know for the population of Yemen (Supplementary Tables 4 and 5).

Supply disruption. We estimated fuel disruption by calculating the average and $95 \%$ uncertainty intervals of monthly fuel imports through Red Sea ports from January to May $2020(n=5)$, before fuel imports being restricted. We calculated the fuel price increase from the November 2017 port closures in Al Hudaydah by taking the median price among diesel, petrol and gas and comparing it between 15 October 2017 and 15 November 2017 price data.

We estimated disruption to desalination capacity by compiling a dataset of locations and water capacity of all known plants in the region and identifying locations reached by the simulated oil spills (Supplementary Table 1). Total water consumption equivalents were computed by multiplying each affected country's share of water amounts by their respective per capita daily usage.

We estimated average and 95\% uncertainty intervals of food disruption on the basis of historical data of imports at Yemeni ports. To calculate the amount of food aid disruption, we used 2019 data showing percentages of total food aid in Yemen originating from Hudaydah and Aden $^{46}$. We then multiplied these percentages by the average of total people targeted for food assistance based on available situation reports from the World Food Programme ranging from March 2020 to February $2021(n=10)$. We used linear interpolation through the quantile algorithm in $\mathrm{R}$ to construct the uncertainty intervals. See Supplementary Table 6 for estimates as reported and as originally calculated.

We estimated fish yield loss on the basis of gridded annual fish yield in the Red Sea and Gulf of Aden from $2016^{56}$. We first filtered for fish yield for only Yemen as a fishing entity, then summed over all types of fishing sectors (artisanal, industrial and so on). We then summed Yemen's fish yield over each gridded cell reached by the simulated spill at each week and season. By default, we included cells only if the oil concentration in them was in the tenth percentile of surface concentration or higher to exclude cells with trace amounts of oil. To assess how threshold values would affect fish yield loss estimates, we repeated the analysis at no threshold and a threshold of the 20th percentile (Supplementary Table 3).

Reporting Summary. Further information on research design is available in the Nature Research Reporting Summary linked to this article.

\section{Data availability}

The raw data used during this study are publicly available and described in the main text. The simulated data are available at https://doi.org/10.7910/DVN/ XPESLB. 


\section{Code availability}

The code used to support this study is available from the corresponding author upon reasonable request. Owing to concerns of potential misuse amid ongoing conflict, the code is not publicly available.

Received: 8 April 2021; Accepted: 20 August 2021;

Published online: 11 October 2021

\section{References}

1. Humanitarian Needs Overview Yemen (United Nations OCHA, 2021); https:// reliefweb.int/sites/reliefweb.int/files/resources/Yemen_HNO_2021_Final.pdf

2. Kleinhaus, $\mathrm{K}$. et al. A closing window of opportunity to save a unique marine ecosystem. Front. Mar. Sci. 7, 615733 (2020).

3. A rusting oil tanker off the coast of Yemen is an environmental catastrophe waiting to happen. Can anyone prevent it? Time (14 May 2021); https://time. com/6048436/fso-safer-yemen-oil-tanker-disaster/

4. Fink, M. D. Naval blockade and the humanitarian crisis in Yemen. Neth. Int. Law Rev. 64, 291-307 (2017).

5. Alles, L. Missiles and Food: Yemen's Man-Made Food Security Crisis (Oxfam, 2017).

6. Sowers, J. \& Weinthal, E. Humanitarian challenges and the targeting of civilian infrastructure in the Yemen war. Int. Aff. 97, 157-177 (2021).

7. Al-Fareh, A. M. The Impact of the War in Yemen on Artisanal Fishing of the Red Sea (LSE, 2018); http://www.lse.ac.uk/Middle-East-Centre

8. Sanders, M. J. \& Morgan, G. R. Review of the Fisheries Resources of the Red Sea and Gulf of Aden FAO Fisheries Technical Paper 304 (FAO, 1989).

9. Tesfamichael, D. et al. (eds) The Red Sea Ecosystem and Fisheries Coral Reefs of the World Vol. 7 (Springer, 2016).

10. Kloog, I., Ridgway, B., Koutrakis, P., Coull, B. A. \& Schwartz, J. D. Longand short-term exposure to $\mathrm{PM}_{25}$ and mortality. Epidemiology $\mathbf{2 4}$ 555-561 (2013).

11. Wei, Y. et al. Short term exposure to fine particulate matter and hospital admission risks and costs in the Medicare population: time stratified, case crossover study. Br. Med. J. 367, 16258 (2019).

12. Burnett, R. T., Smith-doiron, M., Stieb, D., Cakmak, S. \& Brook, J. R. Effects of particulate and gaseous air pollution on cardiorespiratory hospitalizations. Arch. Environ. Health 54, 130-139 (1999).

13. Goldstein, B. D., Osofsky, H. J. \& Lichtveld, M. Y. The Gulf oil spill. N. Engl. J. Med. 364, 1334-1348 (2011).

14. Alexander, M. et al. The Deepwater Horizon oil spill Coast Guard cohort study: a cross-sectional study of acute respiratory health symptoms. Environ. Res. 162, 196-202 (2018).

15. Liu, X. \& Wirtz, K. W. The economy of oil spills: direct and indirect costs as a function of spill size. J. Hazard. Mater. 171, 471-477 (2009).

16. Yemen Commodity Tracker (United Nations OCHA, 2021); https://www. humanitarianresponse.info/sites/www.humanitarianresponse.info/files/ documents/files/ocha20yemen20commodity20track20for20q420202020octobe r20to20january202021_rev1.pdf

17. Millions of Yemenis Days Away from Losing Clean Running Water (Oxfam, 2017); https://www.oxfam.org/en/press-releases/ millions-yemenis-days-away-losing-clean-running-water

18. Jumaan, A. Yemen Humanitarian Crisis: Impact on Population's Health (American Public Health Association, 2020).

19. Huynh, B. Q. \& Basu, S. Forecasting internally displaced population migration patterns in Syria and Yemen. Disaster Med. Public Health Prep. 14, 302-307 (2019).

20. Camacho, A. et al. Cholera epidemic in Yemen, 2016-18: an analysis of surveillance data. Lancet Glob. Health 6, e680-e690 (2018).

21. Minissale, A., Chandrasekharam, D. \& Al-Dubai, M. F. M. in Oceanographic and Biological Aspects of the Red Sea (eds Rasul, N. M. A. \& Stewart, I. C. F.) 195-213 (Springer, 2019)

22. El Bcheraoui, C., Jumaan, A. O., Collison, M. L., Daoud, F. \& Mokdad, A. H. Health in Yemen: losing ground in war time. Glob. Health 14, 42 (2018).

23. Burki, T. Yemen health situation 'moving from a crisis to a disaster'. Lancet 385, 1609 (2015)

24. Kimball, A. M. \& Jumaan, A. Yemen: the challenge of delivering aid in an active conflict zone. Glob. Secur. Health Sci. Policy 5, 65-70 (2020).

25. Moore, R. \& Burns, C. M. The effect of oil spills on workers involved in containment and abatement: the role of the occupational health nurse. AAOHN J. 59, 477-482 (2011).

26. D'Andrea, M. A. \& Reddy, G. K. The development of long-term adverse health effects in oil spill cleanup workers of the Deepwater Horizon offshore drilling rig disaster. Front. Public Health 6, 117 (2018).

27. Looi, M.-K. COVID-19: deaths in Yemen are five times global average as healthcare collapses. Br. Med. J. 370, m2997 (2020).

28. Elnakib, S. et al. Providing care under extreme adversity: the impact of the Yemen conflict on the personal and professional lives of health workers. Soc Sci. Med. 272, 113751 (2021)
29. Oil Spill Cleanup Initiative: Safety and Health Awareness for Oil Spill Cleanup Workers (OSHA, 2010).

30. Kingston, P. F. Long-term environmental impact of oil spills. Spill Sci. Technol. Bull. 7, 53-61 (2002).

31. Peterson, C. H. et al. Long-term ecosystem response to the Exxon Valdez oil spill. Science 302, 2082-2086 (2003).

32. Savary, R. et al. Fast and pervasive transcriptomic resilience and acclimation of extremely heat-tolerant coral holobionts from the northern Red Sea. Proc. Natl Acad. Sci. USA 118, e2023298118 (2021).

33. Al-Majed, A. A., Adebayo, A. R. \& Hossain, M. E. A sustainable approach to controlling oil spills. J. Environ. Manage. 113, 213-227 (2012).

34. Langodan, S. et al. The climatology of the Red Sea - part 2: the waves. Int. J. Climatol. 37, 4518-4528 (2017).

35. Madah, F., Mayerle, R., Bruss, G. \& Bento, J. Characteristics of tides in the Red Sea region, a numerical model study. Open J. Mar. Sci. 5, 193 (2015).

36. Yemen: health, environment and economy remain under threat from stricken oil tanker. UN News (3 June 2021); https://news.un.org/en/ story/2021/06/1093352

37. Hersbach, H. et al. The ERA5 global reanalysis. Q. J. R. Meteorol. Soc. 146, 1999-2049 (2020).

38. Chassignet, E. P. et al. The HYCOM (HYbrid Coordinate Ocean Model) data assimilative system. J. Mar. Syst. 65, 60-83 (2007).

39. NOAA-ORR-ERD/OilLibrary (NOAA, 2020); https://github.com/ NOAA-ORR-ERD/OilLibrary

40. Global Food Prices Database (WFP) (United Nations OCHA, accessed 1 April 2021); https://data.humdata.org/dataset/wfp-food-prices

41. United Nations Verification \& Inspection Mechanism for Yemen (UNVIM) (UNVIM Dashboard, accessed 1 April 2021); https://www.vimye.org/statistics

42. Bin Marshad, S. M. H. Economic Evaluation of Seawater Desalination: A Case Study Analysis of Cost of Water Production from Seawater Desalination in Saudi Arabia. PhD thesis, Heriot Watt Univ. (2014).

43. Al-Mutaz, I. S. Features of multi-effect evaporation desalination plants. Desalin. Water Treat. 54, 3227-3235 (2015).

44. Ahmed, A.-E.-W. Cooperation Council for the Arab States of the Gulf (GCC). In Max Planck Encyclopedia of Public International Law (Oxford Univ. Press, 2014); https://doi.org/10.1093/law:epil/9780199231690/e604

45. Frenken, K. (ed.) Irrigation in the Middle East Region in Figures: AQUASTAT Survey - 2008 (FAO, 2009)

46. Yemen Food Supply Chain (ACAPS, 2020); https://reliefweb.int/sites/reliefweb. int/files/resources/20201216_acaps_yemen_analysis_hub_food_supply_ chain.pdf

47. Beegle-Krause, J. General NOAA Oil Modeling Environment (GNOME): a new spill trajectory model. In Proc. International Oil Spill Conference 865-871 (American Petroleum Institute, 2001).

48. Keramea, P., Spanoudaki, K., Zodiatis, G., Gikas, G. \& Sylaios, G. Oil spill modeling: a critical review on current trends, perspectives, and challenges. J. Mar. Sci. Eng. 9, 181 (2021).

49. Taqi, A. M., Al-Subhi, A. M., Alsaafani, M. A. \& Abdulla, C. P. Estimation of geostrophic current in the Red Sea based on sea level anomalies derived from extended satellite altimetry data. Ocean Sci. 15, 477-488 (2019).

50. Barker, C. H. et al. Progress in operational modeling in support of oil spill response. J. Mar. Sci. Eng. 8, 668 (2020).

51. GNOME User's Manual (NOAA, 2002); https://response.restoration.noaa.gov/ sites/default/files/GNOME_Manual.pdf

52. Kerr, R. A. A lot of oil on the loose, not so much to be found. Science 329 , 734-735 (2010).

53. Draxler, R. R. \& Rolph, G. D. Modeling Results from the HYSPLIT Atmospheric Transport and Dispersion Model (NOAA, 2010); https://www. ready.noaa.gov/hysplit_metadata.html

54. Middlebrook, A. M. et al. Air quality implications of the Deepwater Horizon oil spill. Proc. Natl Acad. Sci. USA https://doi.org/10.1073/pnas.1110052108 (2011).

55. Khomenko, S. et al. Premature mortality due to air pollution in European cities: a health impact assessment. Lancet Planet. Health 5, E121-E134 (2021)

56. Palomares, M. L. D. et al. Fishery biomass trends of exploited fish populations in marine ecoregions, climatic zones and ocean basins. Estuar. Coast. Shelf Sci. 243, 106896 (2020)

\section{Acknowledgements}

B.Q.H. acknowledges support by the National Science Foundation Graduate Research Fellowship under grant no. DGE 1656518 and the National Library of Medicine under Training grant T15 LM 007033. E.T.C. acknowledges support by the National Science Foundation Graduate Research Fellowship under grant no. DGE 1656518. A.M.M. received funding from National Institutes of Health (NIH) NIAID T32AI007433. P.G. was supported by the National Center for Advancing Translational Sciences of the NIH under award no. KL2TR003143. The contents of this article are solely the responsibility of the authors and do not necessarily represent the official views of the NIH. Funding sources had no role in the writing of this manuscript or the decision to submit for publication. We acknowledge the Refugee and Asylum-seeker Health Initiative at 
University of California, San Francisco, for facilitating collaboration between co-authors for this work.

\section{Author contributions}

B.Q.H. conceived the initial study design, performed the analysis and wrote the initial draft. L.H.K., M.V.K., E.T.C., S.B., P.G. and D.H.R. helped revise the study design. A.M.M., A.O.J. and F.M.K. provided crucial contextual information. All authors contributed significantly to interpreting the results and writing the final version of the manuscript.

\section{Competing interests}

The authors declare no competing interests.

\section{Additional information}

Supplementary information The online version contains supplementary material available at https://doi.org/10.1038/s41893-021-00774-8.

Correspondence and requests for materials should be addressed to

Benjamin Q. Huynh.
Peer review information Nature Sustainability thanks Alesia Ferguson, Tor Nordam, Raúl Periáñez and the other, anonymous, reviewer(s) for their contribution to the peer review of this work.

Reprints and permissions information is available at www.nature.com/reprints.

Publisher's note Springer Nature remains neutral with regard to jurisdictional claims in published maps and institutional affiliations.

(c) (i) Open Access This article is licensed under a Creative Commons

Attribution 4.0 International License, which permits use, sharing, adaptation, distribution and reproduction in any medium or format, as long as you give appropriate credit to the original author(s) and the source, provide a link to the Creative Commons license, and indicate if changes were made. The images or other third party material in this article are included in the article's Creative Commons license, unless indicated otherwise in a credit line to the material. If material is not included in the article's Creative Commons license and your intended use is not permitted by statutory regulation or exceeds the permitted use, you will need to obtain permission directly from the copyright holder. To view a copy of this license, visit http://creativecommons. org/licenses/by/4.0/.

(c) The Author(s) 2021 


\section{Reporting Summary}

Nature Research wishes to improve the reproducibility of the work that we publish. This form provides structure for consistency and transparency in reporting. For further information on Nature Research policies, see our Editorial Policies and the Editorial Policy Checklist.

\section{Statistics}

For all statistical analyses, confirm that the following items are present in the figure legend, table legend, main text, or Methods section.

$\mathrm{n} / \mathrm{a} \mid$ Confirmed

$\mathbf{x}$ The exact sample size $(n)$ for each experimental group/condition, given as a discrete number and unit of measurement

$\mathbf{x} \square$ A statement on whether measurements were taken from distinct samples or whether the same sample was measured repeatedly

$\mathbf{x} \square$ The statistical test(s) used AND whether they are one- or two-sided

Only common tests should be described solely by name; describe more complex techniques in the Methods section.

$\mathbf{x} \square$ A description of all covariates tested

$\mathbf{x} \square$ A description of any assumptions or corrections, such as tests of normality and adjustment for multiple comparisons

x A full description of the statistical parameters including central tendency (e.g. means) or other basic estimates (e.g. regression coefficient)

AND variation (e.g. standard deviation) or associated estimates of uncertainty (e.g. confidence intervals)

For null hypothesis testing, the test statistic (e.g. $F, t, r$ ) with confidence intervals, effect sizes, degrees of freedom and $P$ value noted Give $P$ values as exact values whenever suitable.

For Bayesian analysis, information on the choice of priors and Markov chain Monte Carlo settings

For hierarchical and complex designs, identification of the appropriate level for tests and full reporting of outcomes

Estimates of effect sizes (e.g. Cohen's $d$, Pearson's $r$ ), indicating how they were calculated

Our web collection on statistics for biologists contains articles on many of the points above.

\section{Software and code}

Policy information about availability of computer code

Data collection No software or code was used to collect the data.

Data analysis Oil spill simulations were done using pyGNOME (Version 0.5.0) on Python (Version 3.7.6). Air pollution simulation was done using HYSPLIT (Version 5.0.0). Data analysis was conducted on R (Version 3.6.3).

For manuscripts utilizing custom algorithms or software that are central to the research but not yet described in published literature, software must be made available to editors and reviewers. We strongly encourage code deposition in a community repository (e.g. GitHub). See the Nature Research guidelines for submitting code \& software for further information.

Data

Policy information about availability of data

All manuscripts must include a data availability statement. This statement should provide the following information, where applicable:

- Accession codes, unique identifiers, or web links for publicly available datasets

- A list of figures that have associated raw data

- A description of any restrictions on data availability

The raw data used during this study are publicly available and described in the supplementary information section. The simulated data are available at https:// doi.org/10.7910/DVN/XPESLB. 
Please select the one below that is the best fit for your research. If you are not sure, read the appropriate sections before making your selection.
$\mathbf{x}$ Life sciences
Behavioural \& social sciences
Ecological, evolutionary \& environmental sciences

For a reference copy of the document with all sections, see nature.com/documents/nr-reporting-summary-flat.pdf

\section{Life sciences study design}

All studies must disclose on these points even when the disclosure 's negative.

\begin{tabular}{|c|c|}
\hline Sample size & This is unapplicable because our work is a simulation study. No samples or observational data were collected. \\
\hline Data exclusions & No data were excluded from the analysis. \\
\hline Replication & We performed several sensitivity analyses on both our oil spill and air pollution simulations, described in the supplement. \\
\hline Randomization & This is unapplicable because our work is a simulation study and our study design does not incorporate experimental groups. \\
\hline Blinding & This is unapplicable because our work is a simulation study and our study design does not incorporate experimental groups. \\
\hline
\end{tabular}

\section{Reporting for specific materials, systems and methods}

We require information from authors about some types of materials, experimental systems and methods used in many studies. Here, indicate whether each material, system or method listed is relevant to your study. If you are not sure if a list item applies to your research, read the appropriate section before selecting a response.

\begin{tabular}{|c|c|c|c|}
\hline \multicolumn{2}{|c|}{ Materials \& experimental systems } & \multicolumn{2}{|c|}{ Methods } \\
\hline $\mathrm{n} / \mathrm{a}$ & Involved in the study & $\mathrm{n} / \mathrm{a}$ & Involved in the study \\
\hline$x$ & $\square$ Antibodies & $x$ & $\square$ ChIP-seq \\
\hline$x$ & Eukaryotic cell lines & $x$ & $\square$ Flow cytometry \\
\hline$x$ & Palaeontology and archaeology & $x$ & $\square$ MRI-based neuroimaging \\
\hline$x$ & Animals and other organisms & & \\
\hline$x$ & Human research participants & & \\
\hline$x$ & $\square$ Clinical data & & \\
\hline$x$ & $\square$ Dual use research of concern & & \\
\hline
\end{tabular}

